\section{Smart Diabetic Screening and Managing Software, A Novel Decision Support System}

\author{
Ghoddusi Johari M.', Dabaghmanesh M. H. ${ }^{2}$, Zare H. ${ }^{3}$, Safa- \\ eian A. R. ${ }^{3}$, Abdollahifard Gh. ${ }^{\text {* }}$
}

\begin{abstract}
Background: Diabetes is a serious chronic disease, and its increasing prevalence is a global concern. If diabetes mellitus is left untreated, poor control of blood glucose may cause long-term complications. A big challenge encountered by clinicians is the clinical management of diabetes. Many IT-based interventions such ad CDSS have been made to improve the adherence to the standard care for chronic diseases.

Objective: The aim of this study is to establish a decision support system of diabetes management based on diabetes care guidelines in order to reduce medical errors and increase adherence to guidelines.
\end{abstract}

Materials and Methods: To start the process, at first the existing guidelines in the field of diabetes mellitus such as ADA 2017 and AACE guideline 2017 were reviewed, and accordingly, flowcharts and algorithms for screening and managing of diabetes were designed. Then, it was passed on to the information technology team to design software.

Results: The most significant outcome of this research was to establish a smart diabetic screening and managing software, which is an important stride to promote patients' health status, control diabetes and save patients' information as an important and reliable source.

Conclusion: Health care technologies have the potential to improve the quality of diabetes care through IT-based intervention, such as clinical decision support systems. In a chronic disease like diabetes, the critical component is the disease management. The advantages of this web-based system are on-time registration, reports of diabetic prevalence, uncontrolled diabetes, diabetic complications and reducing the rate of mismanagement of diabetes, so that it helps the physicians in order to manage the patients in a better way.

\section{Keywords}

Diabetes Mellitus, Clinical Decision Support System (CDSS), Information Technology, Quality of Care, Clinical Performance in Diabetes Care

\section{Introduction}

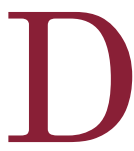
iabetes is a serious chronic disease, and its increasing worldwide prevalence is a global concern. There are nearly 366 million diabetic individuals and it is estimated that 552 million will be affected by 2030 in the world [1]. Diabetes mellitus is one of the top ranking non-communicable diseases in Iran. Approximately $90 \%$ of all people with diabetes have diabetes type 2 [2]. The prevalence of type $2 \mathrm{DM}$ in Iran ranges from $3.5 \%$ to $13.1 \%$ in subjects aged 30 or older

${ }^{1}$ Department of Community Medicine, School of Medicine, Shiraz University of Medical Sciences,

Shiraz, Iran

${ }^{2}$ Endocrine and Metabo-

lism Research Center

Shiraz University Of

Medical Sciences, Shi-

raz, Iran

${ }^{3}$ Yekta Par-

nian mehr Aria IT

Corporation,Shiraz,Iran

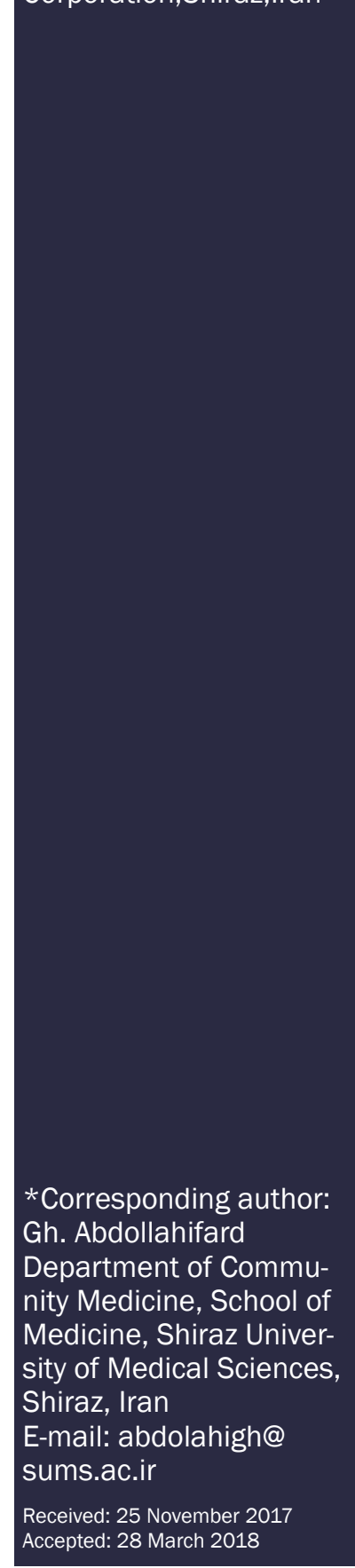


[3]. If diabetes mellitus is left untreated, poor control of blood glucose may cause long-term micro- and macro-vascular complications such as nephropathy, retinopathy and cardiovascular diseases [4].

The World Health Organization projects that diabetes will be the seventh leading cause of mortality till 2030. How to deal with this threat is of a concern [5]. According to American Diabetes Association (ADA), early diagnosis and good-treatment by changing lifestyle, controlling blood glucose and pharmacological interventions are effective in managing diabetes and reducing its complications [6]. There are many clinical guidelines to standardize the diagnosis and treatment processes. That is while, these guidelines with long text documents are difficult to be used by a physician in the clinics [1]. A big challenge encountered by clinicians is how to clinically manage diabetes. Thus, there is a gap between the current care and the documented diabetes care standard [7].

Family physician has a unique position to influence and manage diabetic patients, by moving towards the setting of lifestyle changes and the prevention of diabetes complications. The best care requires the family physician to be competent in managing the complexity of this disease [8].

Many IT-based interventions have been made to improve the adherence to the standard cares for non-communicable diseases. IT increasingly is used in modern medical practices, health care management and medical professional knowledge. One of the areas which decision support system has influenced, is the health care field [2]. Clinical decision support system (CDSS) is a tool which is used to improve the quality of health care by maximizing services and controlling the cost of health care [7], as Maia et al. reported that the implementation of a DSS supporting the treatment of diabetic people in primary care is feasible and the healthcare professionals should consider it helpful [9]. O’Conner et al. in their article reported that evidence suggests that some cost-effective systems have high usage rates and are accepted by both providers and patients [10].

Providing specific evidence-base treatment options for management of different aspects of diabetes saves a great time, encourages good management of different domain of care, and also reduces the likelihood of unhelpful prescriptions [10]. Therefore, the aim of this study is to establish a decision support system of diabetes management based on diabetes care guidelines in order to reduce medical errors and increase adherence to guidelines in some health therapeutic centers in Shiraz, Iran.

\section{Materials and Methods}

\section{Method}

The method in the project consists of two phases. To design a DSS software, articles and countries different databases that have such software were investigated, because in Iran there is no such a database for diabetic patients. To begin the process, the existing guidelines in the field of diabetes mellitus such as ADA 2017 and American Association of Clinical Endocrinologists (AACE) guideline 2017 were reviewed, and accordingly, flowcharts and algorithms screening and managing of diabetes were designed. The final flowcharts were reviewed by one endocrinologist and one community medicine specialist, then, it was passed on to the information the technology team to design the software. The software is web-based, and it is designed based on ASP. Net MVC server technology version 4.0.3, Razor engine, SQL Server database, HTML 5 and CSS 3 world standard and Ajax technology.

The software interface was designed by reviewing the concept to ensure consistency with flowcharts and best clinical practice. In addition, user friendliness and ease of data entry were also considered. Since this software has 
the capability of both screening and managing diabetes, the initial and subsequent evaluation started from the basic knowledge of patients. It consists of demographic data and past medi- cal history. During this phase, diabetic patients are diagnosed, and specific questions and drug history are asked (Figures 1, 2, 3, 4).

Physical activity status based on type and se-

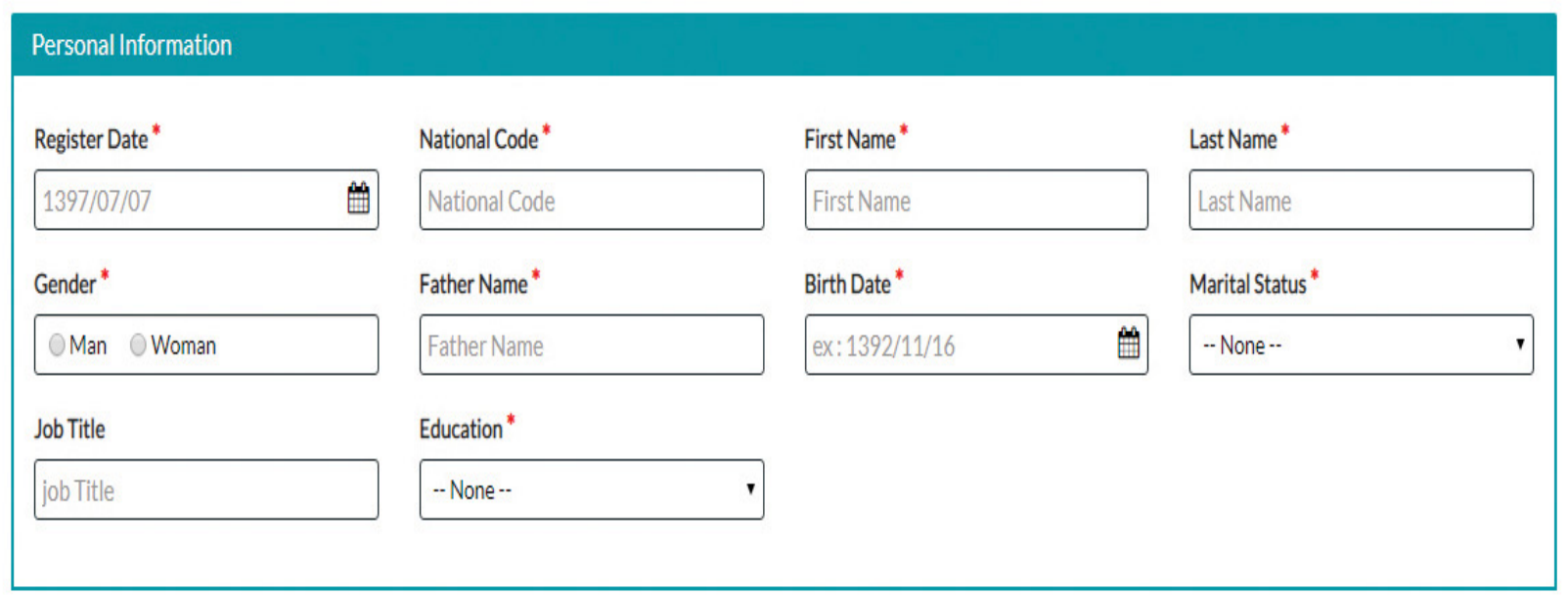

\section{?????}

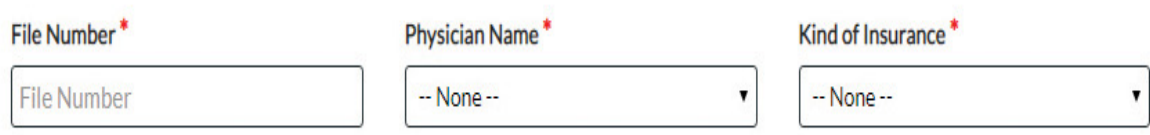

Figure 1: presentation of Demographic data

\section{Past Medical History}

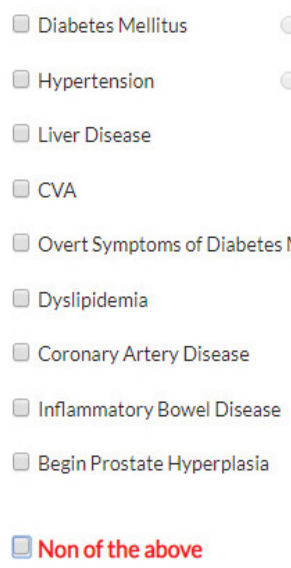

Figure 2: Presentation of past medical history 
Diabetes Mellitus

\section{History}

Teeth and Oral exam

OYes ONo

Anually Retinal exam

OYes ONo

Previous Amputation

OYes ONo

Previous Foot Ulcer

OYes ONo

InFluenza Vaccination

OYes ONo

Pnemoccocal Vaccine Vaccination

OYes ONo

Psychological evaluation:Consult is Needed

OYes ONo

Do you have diabetic complication yet?

Figure 3: Specefic question taken from diabetic patients

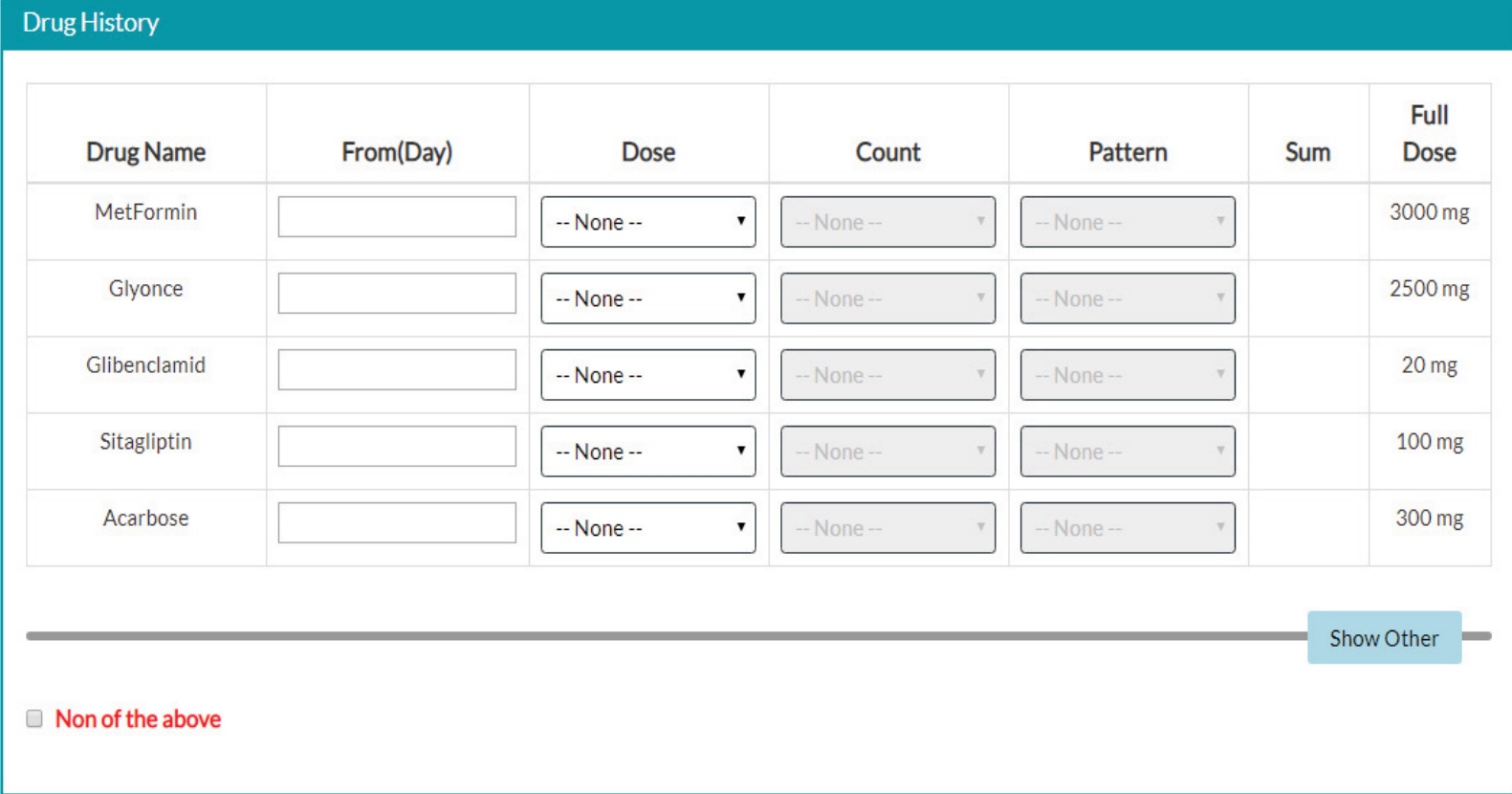

Figure 4: Drug box for diabetic patients to save current medications 
verity according to "Physical Activity Guidelines 2017" was designed [11]. A Type of activities with the title of vigorous and moderate, along with the variety of activities in a week was offered via software. Through this step, the physical activity status was calculated and considered for the final plan (Figure 5). Smok- ing and family history were furthermore considered (Figures 6, 7). For diabetic patients, complete and precise examinations were requested. Moreover, a segment for storing laboratory tests such as specific diabetic test, FBS, 2hpp, HbAlc and other routine laboratory tests for diabetics were designed (Figures

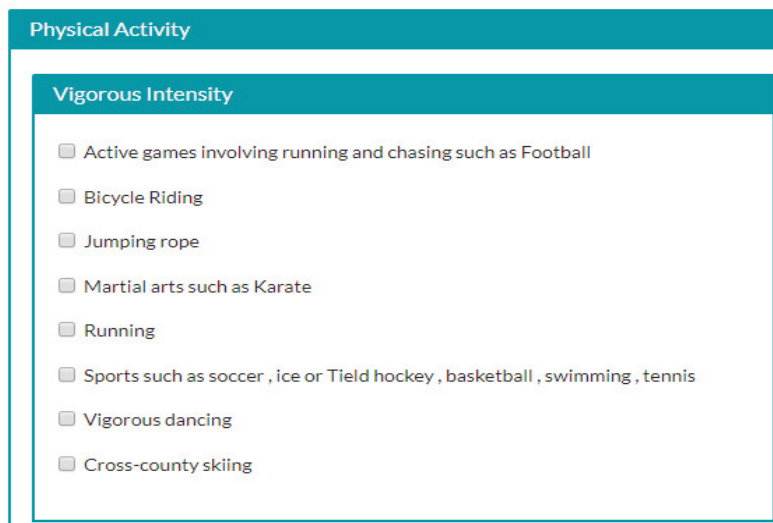

\section{Moderate Intensity}

$\square$ Canoeing, hiking, stakebording, rollerblading

$\square$ Brisk walking

$\square$ Bicycle riding (Stationary or raad bike)

$\square$ House work and yard work, such as sweeping or pushing a lawn mower

$\square$ Games that require catching and throwing, such as Basball , volleyball

Figure 5: presentation of diverse types of physical activity

\section{Smoke (Or other tobacco products)}

OYes $\odot$ No

Figure 6: presentation smoking status

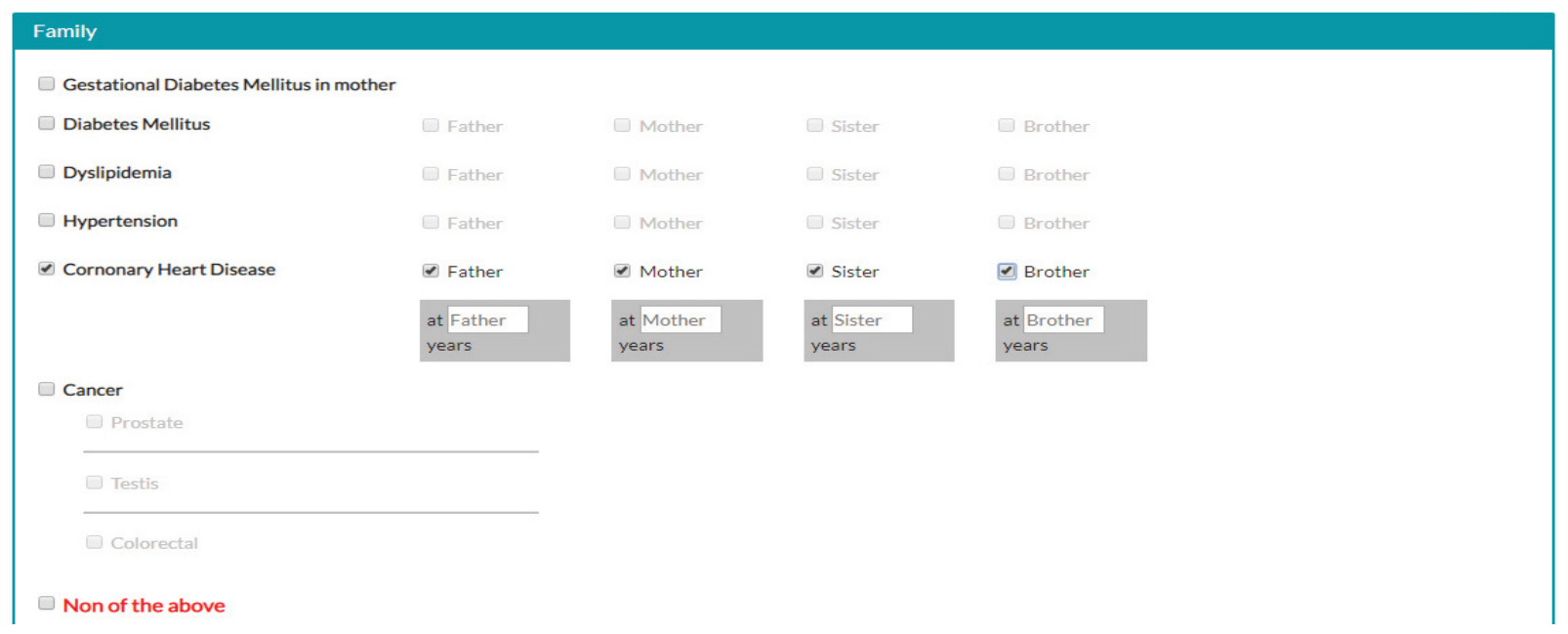

Figure 7: Presentation of Family history of patients 
$8,9,10,11)$

Furthermore, in specific diabetic patients' examinations, one part was related to a foot exam. In addition to this examination, if a foot ulcer was present, a section would be designed for the foot image in several ways by simulta-

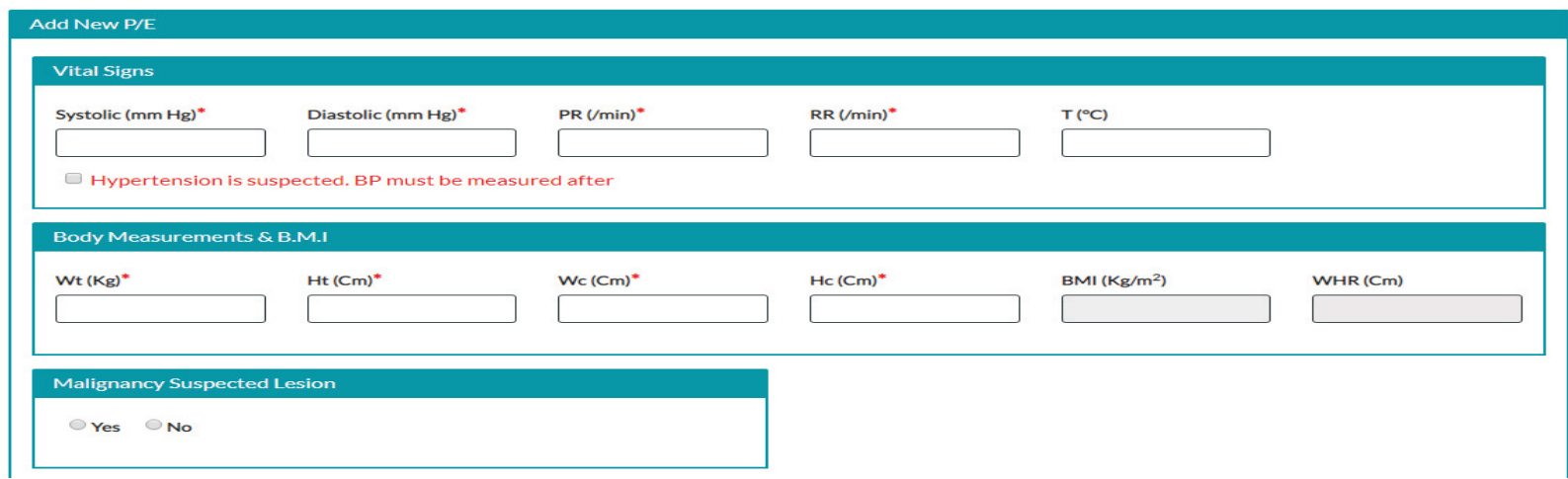

Figure 8: First part of physical exam for patients

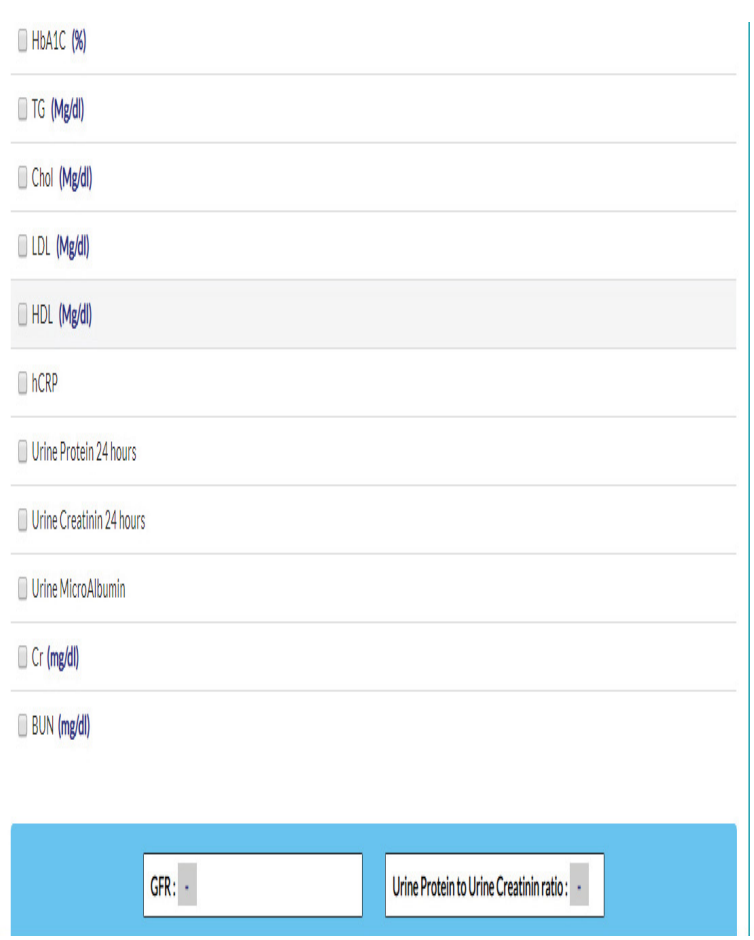

Figure 9: First part of diabetic Laboratory test

neous capture, saving pictures in the archive; otherwise, schematic design of foot image was designed and due to the severity of ulcer, it had the possibility to be marked with three different colors (red, yellow and green). This was implemented in order to have data for the patient's next referral (Figures 12, 13, 14, 15). Another specific test for diabetic foot is $10 \mathrm{~g}$ -

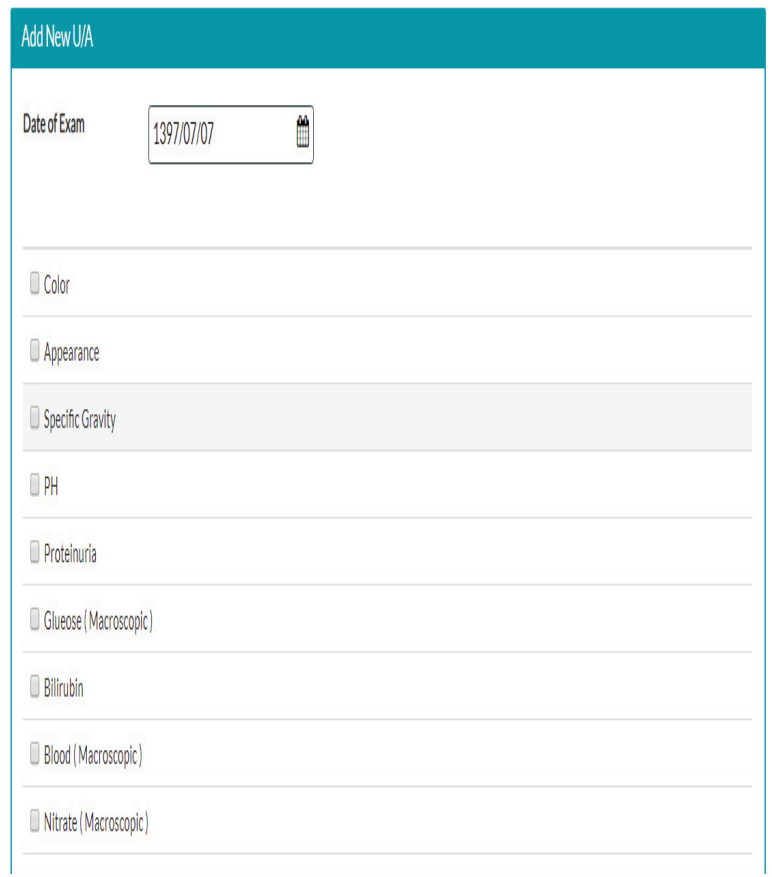

Figure 10: Urine Analysis (the second part of diabetic laboratory test)

Monofilament test considered in this section; if a patient had an impaired test, this could mark the area of impairment in the schematic design, checking pedal pulses and evaluating claudication would be requested [12, 13](Figure 16).

Since the best diabetes care needs paying attention to manage blood glucose, blood pres- 
sure, lipid profiles and smoking status, BMI, prescription of Aspirin, Statin and screening for retinopathy, neuropathy, nephropathy and vascular complications, and immunization, all were considered in the design of this software to help the physician in order to make an exact

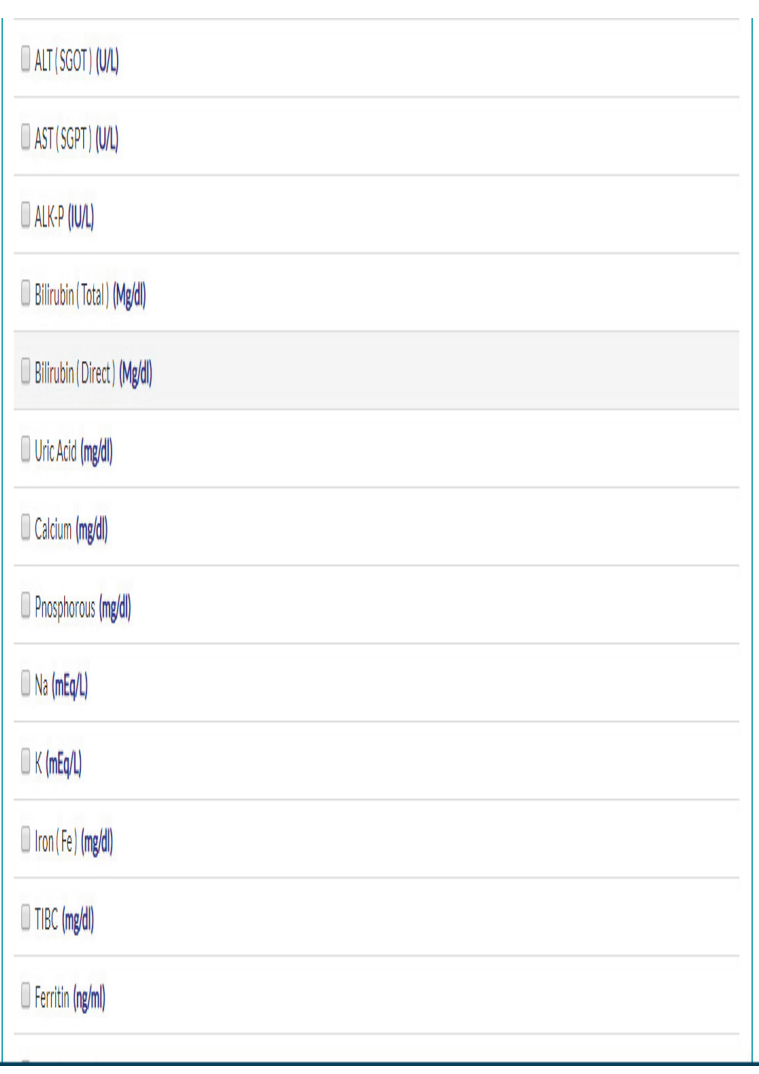

Figure 11: The third part of laboratory tests

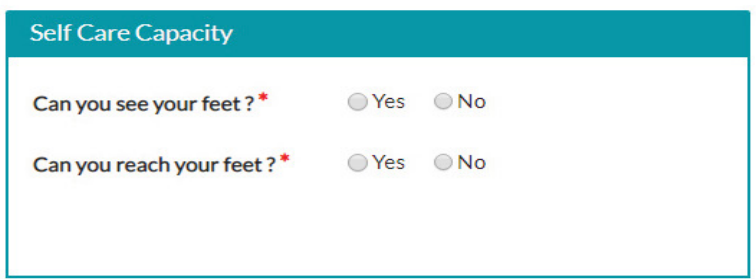

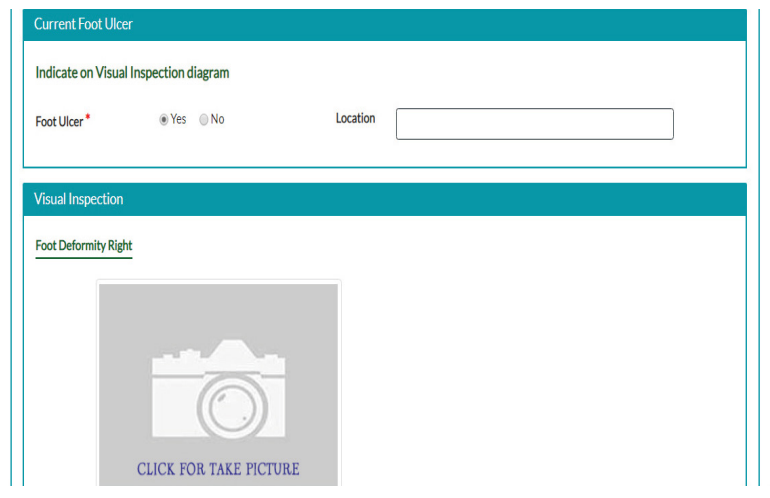

Figure 12: The specific diabetic foot exam, first section

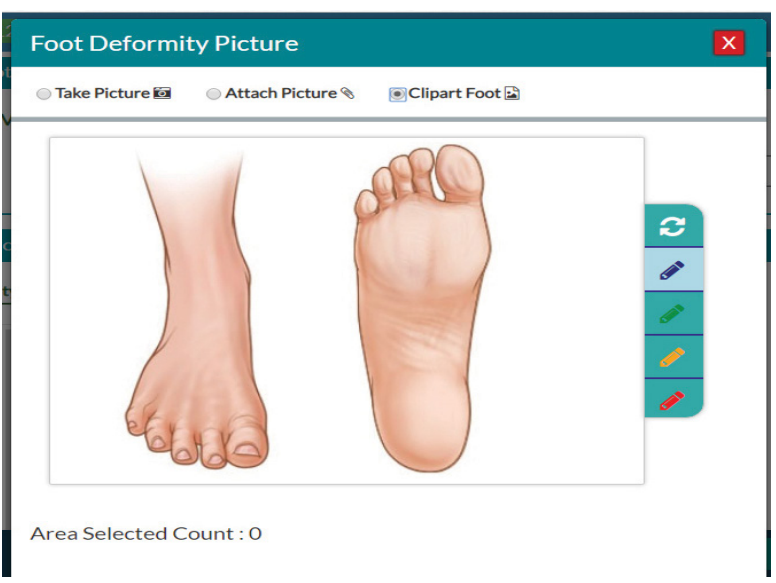

Figure 13: Schematic design of foot image to detection of ulcer

\section{Footwear Check}

\begin{tabular}{|c|c|c|}
\hline Style: ${ }^{*}$ & Good & Poor \\
\hline Condition:* & Good & Poor \\
\hline Fit: * & Good & Poor \\
\hline
\end{tabular}

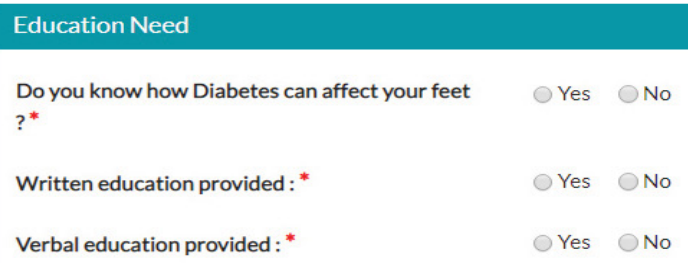

Figure 14: Specefic questions related to diabetic foot exam 


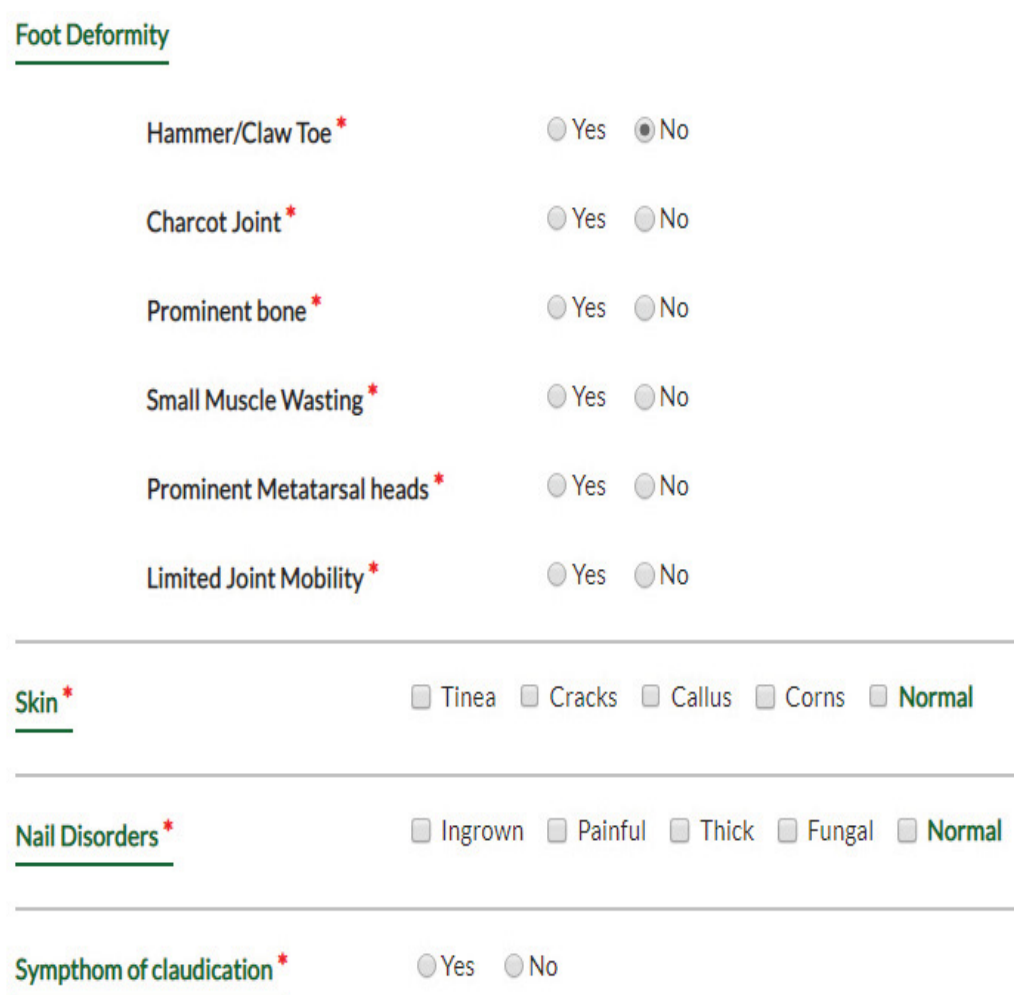

Figure 15: Specefic question related to diabetic foot exam

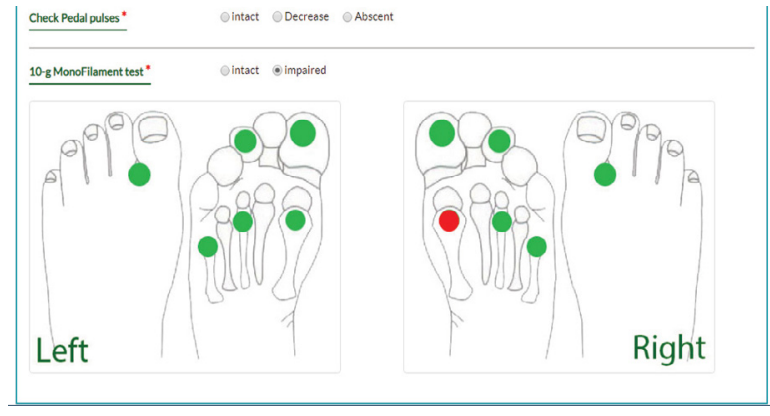

Figure 16: Monofilament test

prescription at the time of patient's visit or during the next followup. The CDSS application generates specific recommendations based on the given data. Next, proper selection of antidiabetic drug, warning about poor glycemic control by suggesting possible adjustment, recommendations for the assessment of inappropriate medication doses, or uncontrolled hyper-glycaemia, prescription of Aspirin and
Statins to those who have indications of consuming these drugs, and recommend screening for micro- and macro-vascular complications of diabetes.

The most important feature of this software is that it can recommend Hypoglycemic agents at the time of plan presentation. Each medication is shown based on the common and existence forms, the usage patterns and maximum permissible doses in a separate box (Figure 17). In patients who have to start oral antidiabetic agents, software considers "GFR" as a point to set up medication doses as required, and also does not permit the physician to prescribe medication more than permissible full doses.

Another noticeable point about this software is that it can consider Aspirin and Statins for those who have necessary risk factors according to ADA 2017. Moreover, this software has the capability to offer Statins in different types 


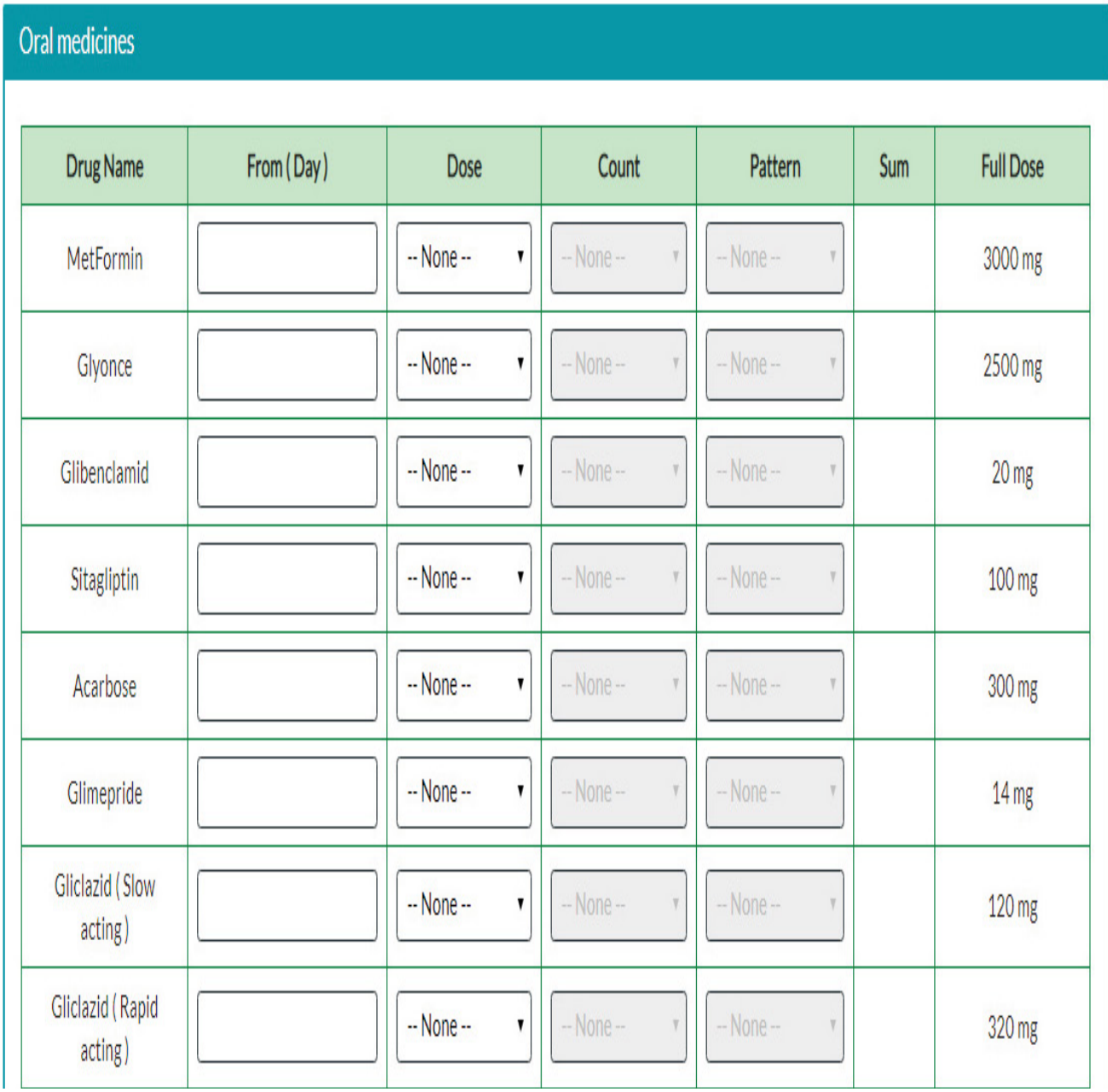

Figure 17: Presentation of Hypoglycemic agents

and doses if necessary, according to the existing risk factors.

In this regard, if a physician misjudges patients risk status or makes a mistake due to time limitation, CDSS can be of great assistance.

To test the software, 50 scenario-based cases were prepared and entered into the software as a pilot. Creating these scenario-based patients were done according to three categories: 1normal group patients (with 10 patients above and 10 under the age of 45 years old), 2- prediabetic (10 patients), and 3-diabetic patients (consisting of 10 with normal and 10 with abnormal range of blood glucose). Different as- pects of patients' conditions like past medical history such as coronary heart disease, lipid $\mathrm{dx}, \mathrm{HTN}$, existence of micro- and macro-vascular complications with diverse drug history, smoking and physical activity status were considered. The final decisions for each fabricated case were reviewed by an endocrinologist, and then all data for each patient were entered into the software. Afterwards, the decisions made by CDSS were checked by true decisions.

\section{Results}

The most significant outcome of this research was to establish a smart diabetic screening and managing software, which is an important 
stride to promote patients' health status, control diabetes, and save patients' information as an important and a reliable source.

Based on previous research and multiple reviews, existing diabetes guideline were studied, hence, flowcharts of screening and managing diabetes mellitus were designed, and then passed to information technology team; the software was designed accordingly .

Considering patients' data, we can have a comprehensive database of all patients, which is accessible if necessary.

All individuals who have indications of screening, after entering the information, according to the existing criteria, would be diagnosed and screened. For high risk people with diabetes, tests and a necessary workup can be requested, and for those who have indications, medical therapy is recommended.

The diabetic patients, who have oral medical therapy, are assessed through test results, and the current oral medication patients have the normal blood glucose status according to the guideline definition, the continuation of the treatment with the mentioned initial statins and Aspirin dosage is suggested.
In this situation, patients' followup should be considered every three months with specific diabetic tests such as FBS, 2hpp and HbAlc.

In patients with uncontrolled hyperglycemia, if a patient is treated with one medication, increasing dose of drug till maximum dose is suggested.

If the patient is consuming two medication, increasing the second drug till maximum dose is done, and if in this situation, the patient still has uncontrolled hyperglycemia, and both medication reach maximum dosage, starting the third drug is suggested.

However, if hyperglycemia remains uncontrolled, increasing the third drug till maximum dose will be suggested. In the absence of controlled blood glucose, the patient is referred to an endocrinologist to start Insulin regimen (reference ADA). All patients, during followup in case of drug replacement, are reminded monthly. During this procedure, patients' followup is performed according to fasting plasma glucose, $2 \mathrm{hpp}$ and $\mathrm{HbA} 1 \mathrm{c}$. In the first visit, ophthalmologist consult is requested for all diabetic patients and according to the indications, nephrology, neurology and vascular sur-

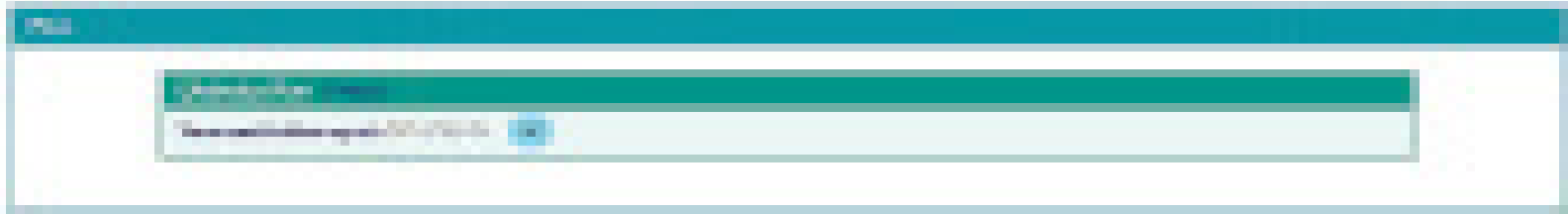

Figure 18: Sample of scenario based case planning, one below 45 year old without risk factor

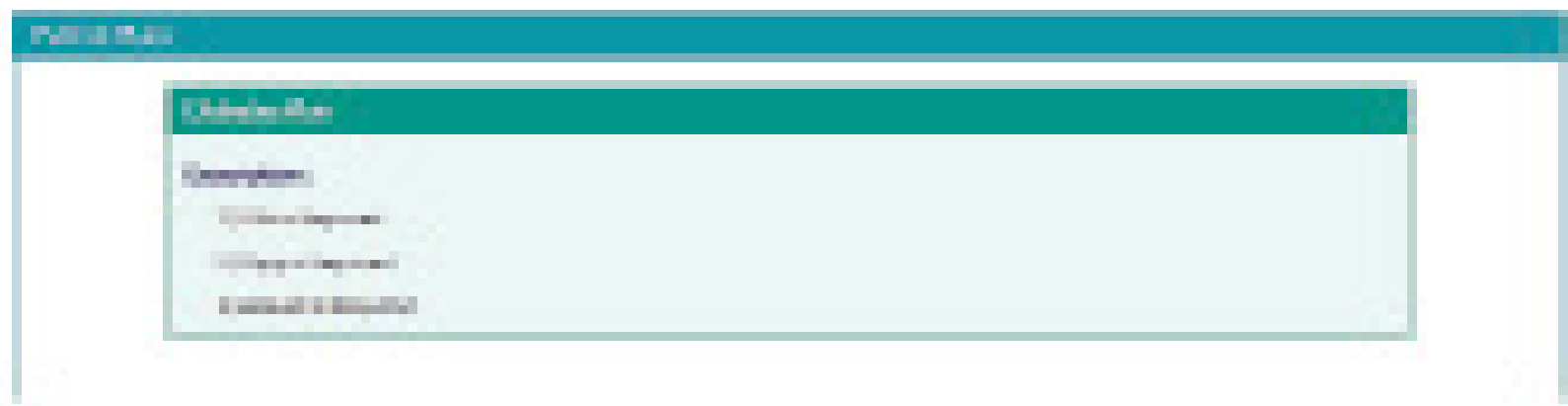

Figure 19: Sample of scenario based case planning, below 45 years old, with risk factor 


\section{1)}

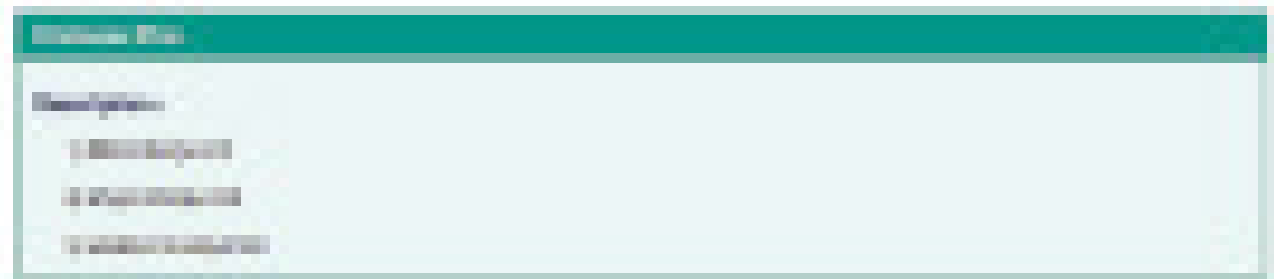

Figure 20: Sample of scenario based case planning, one without any medical history,above 45 years

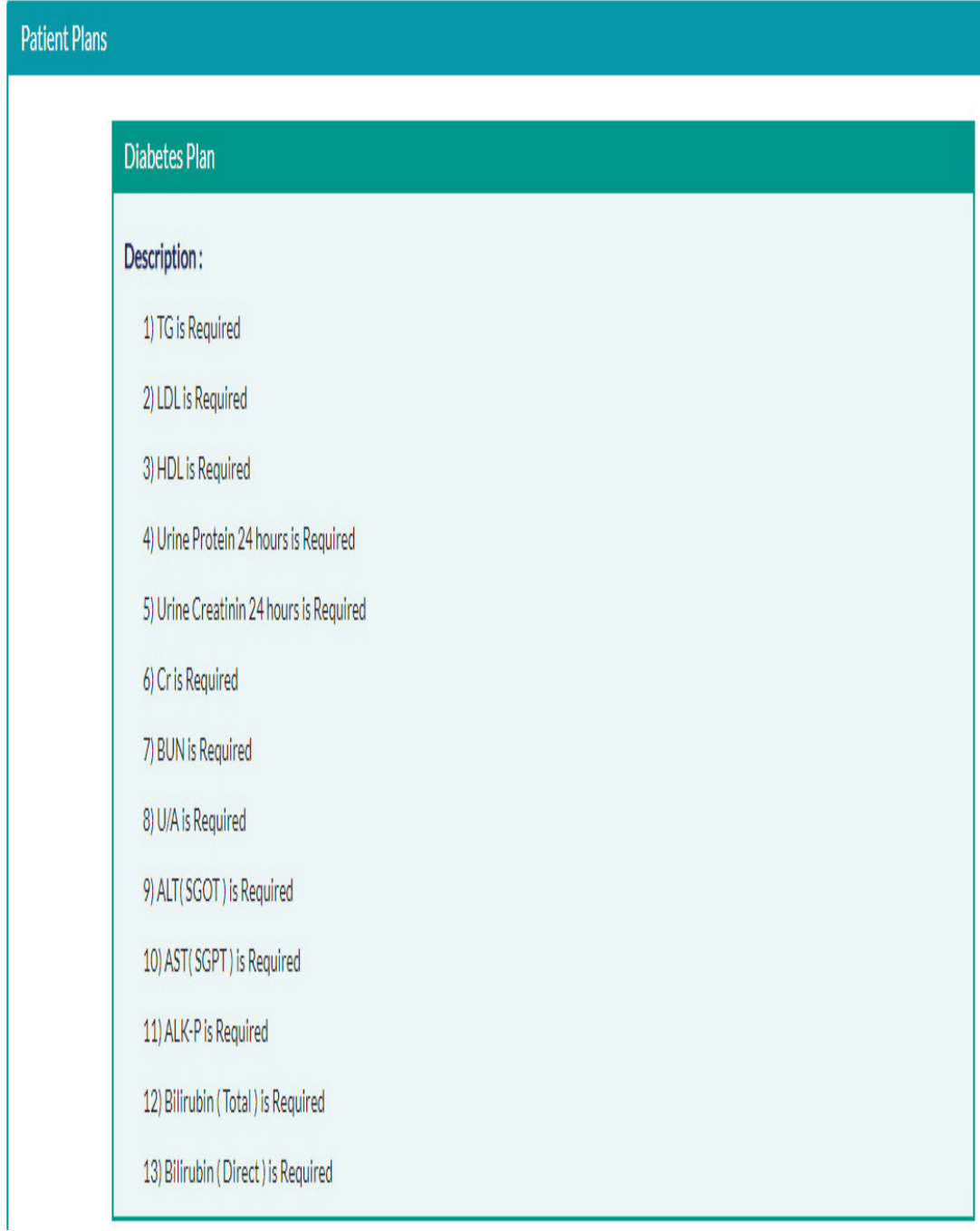

Figure 21: Sample of scenario based case planning, prediabetic patient. (first part) 


Diabetes Plan ("New)
Description:
$\square$ Recheck: FBS, 2hpp
Start Intensive Diet
$\square$ Increase physical activity
$\square$ Self managment and Self monitoring plan
$\square$ Refer to Nephrologist
$\square$ MetFormin
(A The patient has High AST)
Drug History:
Last Prescription:
Prescription Drugs:
Your next Follow up at: $1397 / 08 / 19$

Figure 22: Sample of scenario based case planning, prediabetic patients, second part

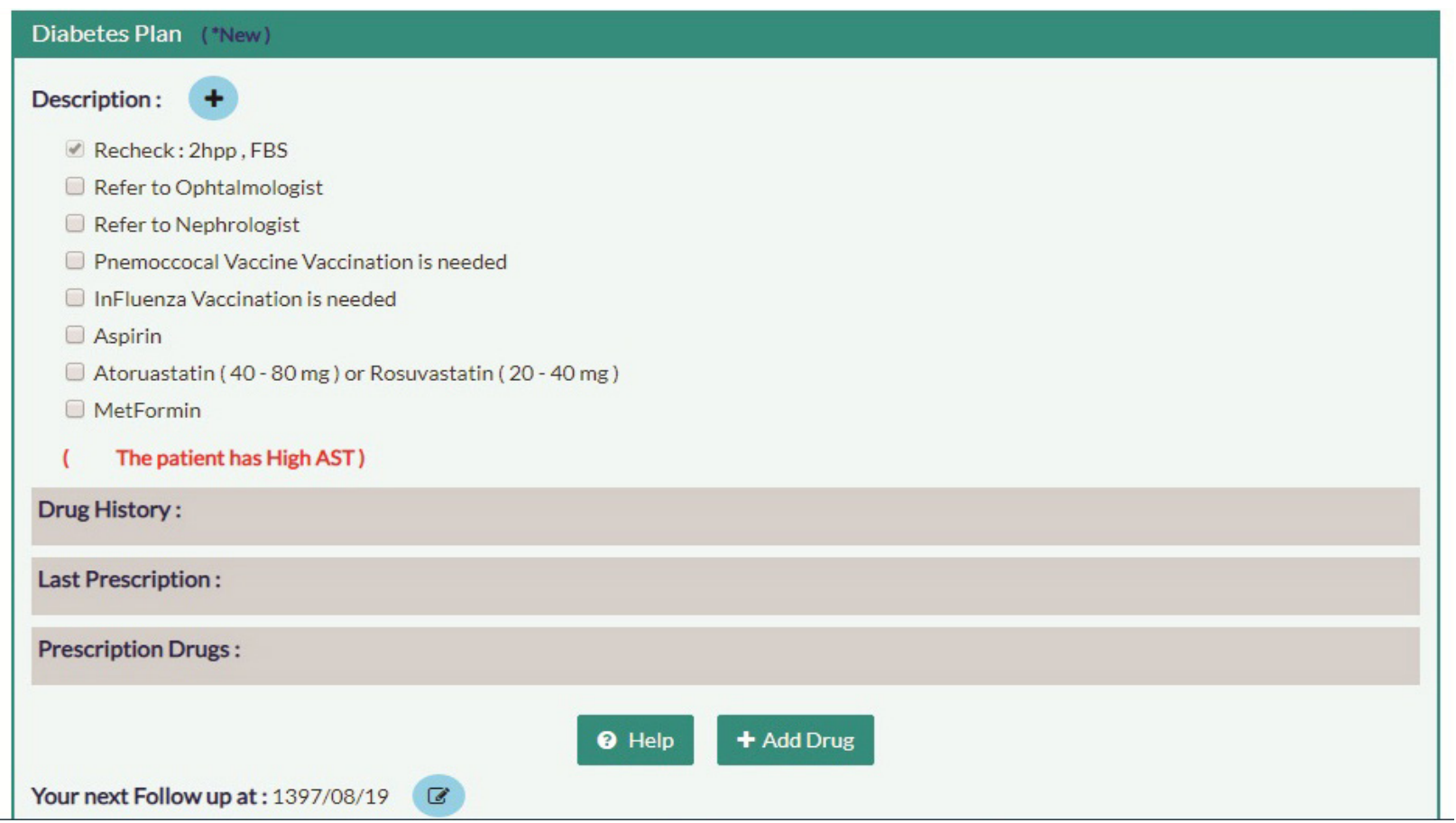

Figure 23: Sample of scenario based case planning, a diabetic patients with controlled hyperglycemia

gery consultations are recommended.

Hence, the indications of these consultations are according to specific tests requested by the physical exam section.

In this study, 50 scenario-based cases classi- fied into three groups that they were designed according to plasma glucose, and each group was assessed with the software separately, thus the validity of the software was approved. In the following section, the samples of plans 


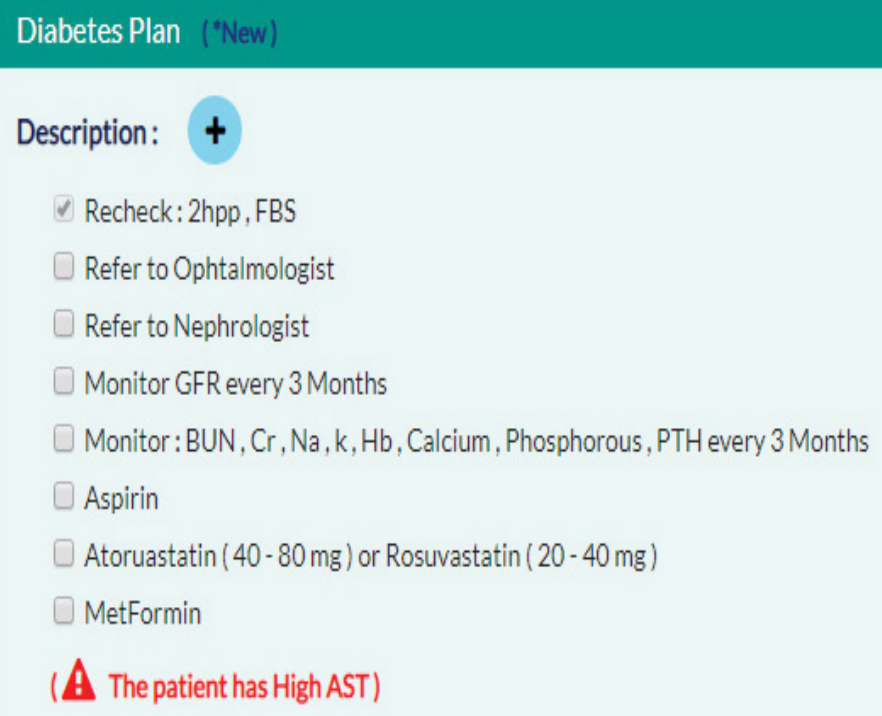

Figure 24: Sample of scenario based case planning, one diabetic patients without control of hyperglycemia

are presented in Figures 18, 19, 20, 21, 22, 23, 24 , respectively.

\section{Discussion}

Managing diabetes, because of substantial resources and knowledge that are needed, is so challenging [8]. Current diabetes care practices sometimes do not reach the recommended advice.

CDSS can improve the quality of diabetic care by using reminders and monitoring [14]. In chronic diseases like diabetes, documentation has an important role in disease management. The availability of a population-based registry system can be a solution for the health service providers, and a guidance to strength- en the diabetic CDSS. Nonetheless, short and long-term potential benefits of a CDSS should be weighed against the costs, because it needs the installation of the software and networking capabilities, which requires planning.

Therefore, the effective use of CDSS in clinical settings should be combined with changes in work processes such as changes in nursing roles and provision of health care providers to encourage the adoption of CDSS in the clinical setting [15].

In healthcare, CDSS can play an important role. The health care provider's clinical decisions are sometimes based on clinical guidance and evidence-based documented standards. However, intelligent methods make a 
choice for physicians and health care team to collect information and process them in different ways in order to assist diagnosis and treatment. CDSS can be applied in the healthcare in different situations such as the analyses of patients' past medical history for diagnosis and review of common characteristics and trends in medical record databases [16].

Ideal outpatient's CDSS can identify diabetic patients with the highest potential benefits by changing the pattern in management; identifying a patient's specific clinical domains is not a goal, suggesting patients appropriate evidence-based treatment options.

IT-based interventions along with usual care are associated with glycemic control improvement in diabetic patients.

Vast implementation of electronic medical or health records has catalyzed CDSS, which can result in the improvement of diabetes care quality [7].

Maya et al. demonstrated that the usage of DSS to support the management in primary care is feasible and the healthcare team considered it to be useful [9].

A systematic review by Riazi et al. showed that information technology-based interventions along with usual care resulted in glycemic control improvement with various efficacy on clinical outcomes in individuals with diabetes [17].

According to Siriwardena et al. study, telemedicine appears to be a good alternative to current therapy in diabetic care [18].

Syed Mustafa Ali et al. in a randomized controlled trial suggested that CDSS could improve clinical outcomes of diabetes care in a moderate fashion, and it has the potential to increase adherence to the standardized diabetic care [7].

DSS data must be collected in an electronic database, which has the capabilities of storage, retrieval and analysis.

While a CDSS can improve documentation, it may not improve patients' compliance and the capacity that depends on close collaboration between patients and health care providers [19]. By integrating CDSS in clinical work practices, it can generate better results (increasing HbA1c test); however, it cannot guarantee the improved clinical outcomes such as lowering HbA1C [20].

Despite evidence of positive impact on glycemic control in diabetic patients, telemedicine still remains uncommon due to factors such as the absence of specific regulation in many countries, the difficulty in incorporating it into the work routine, and health care team resistance [9].

Finally, lack of health system information technology in some areas such as small cities is an obstacle for the accurate and best assessment of changes in the clinical decisions and process indicators such as the number of patients' referrals to specialists [19].

\section{Conclusion}

The advantages and benefits of this webbased system are on-time registration, reports of diabetic prevalence, uncontrolled diabetes, diabetic complications and reducing the rate of mismanagement of diabetes, which can help physicians to manage patients in a better way.

\section{Acknowledgment}

It should be mentioned that this survey is based on a thesis by Dr. Masoumeh Ghoddusi Johari for completing Community Medicine residency. The authors wish to thank Mr. H. Argasi at the Research Consultation Center of Shiraz University of Medical Sciences for his invaluable assistance in editing this manuscript.

\section{Conflict of Interest}

All authors declare that they have no conflict of interest.

\section{References}

1. El-Sappagh S, Elmogy M. A Decision Sup- 
port System for Diabetes Mellitus Management. Diabetes Case Rep. 2016;1:2.

2. RRasoolimoghadam M, Safdari R, Ghazisaeidi M, Maharanitehrani M, Tahmasebiyan S. Designing Decision Support System to Detect Drug Interactions Type 2 Diabetes. Acta Inform Med. 2015;23:336-8. doi: 10.5455/aim.2015.23.336-338. PubMed PMID: 26862240; PubMed Central PMCID: PMC4720826.

3. Rahmanian K, Shojaei M, Sotoodeh Jahromi $A$. Relation of type 2 diabetes mellitus with gender, education, and marital status in an Iranian urban population. Rep Biochem Mol Biol. 2013;1:64-8. PubMed PMID: 26989710; PubMed Central PMCID: PMC4757057.

4. Jarab AS, Alqudah SG, Mukattash TL, Shattat G, Al-Qirim T. Randomized controlled trial of clinical pharmacy management of patients with type 2 diabetes in an outpatient diabetes clinic in Jordan. $J$ Manag Care Pharm. 2012;18:516-26. doi: 10.18553/jmcp.2012.18.7.516. PubMed PMID: 22971205.

5. World Health Organization(WHO) [Internet]. 2017.

6. Herman WH, Kalyani RR, Cherrington $A L$, Coustan DR, Boer Id, Dudl RJ, et al. Professional Practice Committee. Diabetes Care. 2017;40:S36.

7. Ali SM, Giordano R, Lakhani S, Walker DM. A review of randomized controlled trials of medical record powered clinical decision support system to improve quality of diabetes care. Int J Med Inform. 2016;87:91100. doi: 10.1016/j.ijmedinf.2015.12.017. PubMed PMID: 26806716.

8. Fogelman Y, Goldfracht M, Karkabi K. Managing Diabetes Mellitus: A Survey of Attitudes and Practices Among Family Physicians. J Community Health. 2015;40:1002-7. doi: 10.1007/s10900015-0024-2. PubMed PMID: 25877332; PubMed Central PMCID: PMC4556738.

9. Maia JX, de Sousa LA, Marcolino MS, Cardoso CS, da Silva JL, Alkmim MB, et al. The Impact of a Clinical Decision Support
System in Diabetes Primary Care Patients in a Developing Country. Diabetes Technol Ther. 2016;18:258-63. doi: 10.1089/ dia.2015.0253. PubMed PMID: 26840128.

10. O'Connor PJ, Sperl-Hillen JM, Fazio CJ, Averbeck BM, Rank BH, Margolis KL. Outpatient diabetes clinical decision support: current status and future directions. Diabet Med. 2016;33:734-41. doi: 10.1111/ dme.13090. PubMed PMID: 27194173; PubMed Central PMCID: PMC5642968.

11. To the Minister of Health, Welfare and Sport. Physical activity guidelines 2017. Heath Concil of the Netherlands. No. 2017/08e. 2017.

12. Damir A. Clinical assessment of diabetic foot patient. J Int Med Sci Acad. 2011;24:199-203.

13. Apelqvist J, Bakker $\mathrm{K}$, van Houtum WH, Schaper NC, International Working Group on the Diabetic Foot Editorial B. Practical guidelines on the management and prevention of the diabetic foot: based upon the International Consensus on the Diabetic Foot (2007) Prepared by the International Working Group on the Diabetic Foot. Diabetes Metab Res Rev. 2008;24 Suppl 1:S181-7. doi: 10.1002/dmrr.848. PubMed PMID: 18442189.

14. McGlynn EA, Asch SM, Adams J, Keesey J, Hicks J, DeCristofaro A, et al. The quality of health care delivered to adults in the United States. N Engl J Med. 2003;348:2635-45. doi: 10.1056/NEJMsa022615. PubMed PMID: 12826639.

15. Crosson JC, Ohman-Strickland PA, Cohen DJ, Clark EC, Crabtree BF. Typical electronic health record use in primary care practices and the quality of diabetes care. Ann Fam Med. 2012;10:221-7. doi: 10.1370/afm.1370. PubMed PMID: 22585886; PubMed Central PMCID: PMC3354971.

16. Raz I, Prato SD, Home P, Schnell 0 . The World Congress on Clinical Trials in Diabetes 2016. Berlin, Endocrine Abstracts; 2016.

17. Riazi $H$, Larijani B, Langarizadeh $M$, 
Shahmoradi L. Managing diabetes mellitus using information technology: a systematic review. J Diabetes Metab Disord. 2015;14:49. doi: 10.1186/s40200015-0174-x. PubMed PMID: 26075190; PubMed Central PMCID: PMC4465147.

18. Siriwardena LS, Wickramasinghe WA, Perera KL, Marasinghe RB, Katulanda P, Hewapathirana R. A review of telemedicine interventions in diabetes care. $J$ Telemed Telecare. 2012;18:164-8. doi: 10.1258/jtt.2012.SFT110. PubMed PMID: 22362832.

19. Morrow DG, Conner-Garcia T, Graumlich JF, Wolf MS, McKeever S, Madison
A, et al. An EMR-based tool to support collaborative planning for medication use among adults with diabetes: design of a multi-site randomized control trial. Contemp Clin Trials. 2012;33:1023-32. doi: 10.1016/j.cct.2012.05.010. PubMed PMID: 22664648; PubMed Central PMCID: PMC3408818.

20. Meigs JB, Cagliero E, Dubey A, Murphy-Sheehy P, Gildesgame C, Chueh $\mathrm{H}$, et al. A controlled trial of web-based diabetes disease management: the MGH diabetes primary care improvement project. Diabetes Care. 2003;26:750-7. PubMed PMID: 12610033. 